\title{
Editorial
}

\section{Earth Materials and Environmental Applications 2016}

\author{
Zhaohui Li, ${ }^{1,2}$ Guocheng Lv, ${ }^{1}$ and Jianxi Zhu ${ }^{3}$ \\ ${ }^{1}$ Beijing Key Laboratory of Materials Utilization of Nonmetallic Minerals and Solid Wastes, National Laboratory of Mineral Materials, \\ School of Materials Science and Technology, China University of Geosciences, Beijing, 29 Xueyuan Road, Beijing 100083, China \\ ${ }^{2}$ Geosciences Department, University of Wisconsin-Parkside, Kenosha, WI 53144, USA \\ ${ }^{3}$ Guangzhou Institute of Geochemistry, CAS 511 Kehua Street, Tianhe, Guangzhou 510640, China \\ Correspondence should be addressed to Zhaohui Li; li@uwp.edu
}

Received 5 January 2017; Accepted 5 January 2017; Published 26 January 2017

Copyright (c) 2017 Zhaohui Li et al. This is an open access article distributed under the Creative Commons Attribution License, which permits unrestricted use, distribution, and reproduction in any medium, provided the original work is properly cited.

Since the publication of the 1st special issue on Earth Materials and Environmental Applications in Adv. Mater. Sci. Eng. in 2015, positive feedbacks and needs to expand the scope of research lead to the call for papers and eventually publication of this special issue. In this special issue, we have a collection of 13 papers selected among 29 submitted manuscripts. This special issue focuses more on engineering applications, including from soil erosion prevention and evaluation of fly ash use to mine tailing control.

In the area of controlling soil erosion in arid land such as Saudi Arabia, remote sensing techniques in combination with Geographic Information Systems (GIS) were applied to reclassify soil erosion risk maps, confirming the role of Revised Universal Soil Loss Equation for calculating and predicting soil erosion. Lime stabilization of clayey road base soil with high water content and its improvement with geosynthetics reinforcement and comparisons of these two different improvement methods were made. And the method of improvement with lime and then reinforcement with geosynthetics yields better results on these types of soils. Siltstones from flysch rock masses, Istria Peninsula, Croatia, are highly susceptible to weathering, which causes rapid changes in the geotechnical properties and durability. Laboratory testing showed that the standardized slake durability index was not sufficient enough to classify the durability of weak rock masses such as siltstones. Therefore, the durability of siltstone samples of different weathering grades was quantified from the fragment size distribution after each of five slaking cycles.
Proper dispose of fly ash with high lime content is an issue. Mixing the fly ash collected from Yeniköy thermal power plants in Turkey with local soil Ankara clay could change the geotechnical properties of the clay, resulting in an increase in cohesion value and decrease of free swelling index. Similarly, application of coal ash from Indonesia to postmine land could reduce the soil erosion significantly with an enhanced water retention capacity. As fly ash, used as a binder for Portland cement, often contains heavy metals, the leachability of the heavy metals decreased with increasing curing time.

Engineering tests were conducted to evaluate the use of cement fly ash gravel (CFG) composite foundation in consolidating saturated mine tailings dam. The distribution of earth pressure and pile stress is relatively homogeneous and stable over depth and load, while the development of CFG composite foundation bearing capacity is insufficient, in which the developed bearing capacity of CFG piles is less than $50 \%$ of its characteristic value. The deformation modulus and thickness of cushion exert significant influence on pile-soil stress ratio and integral bearing capacity of CFG composite foundation.

Compacting tests, the resilient modulus tests, the California bearing ratio tests, and permeability tests were carried out on crushed red-bed soft rock mixtures to evaluate their use as materials for highway construction. Studies on mechanical properties of red soil in Sichuan showed that the water-softening effect is more obvious with higher degree of weathering and the changes of the microstructure and 
material composition seem to be the key parameters for the reduction of its mechanical strength.

Aluminum dross is an industrial waste from aluminum refining industry and classified as toxic substances. However, the disposal of dross as a waste is a burden to aluminum manufacturer industries due to its negative effects to the ecosystem, surface, and ground water. A study on the utilization of aluminum dross by alkali treatment showed that it had the potential to be converted into other useful material such as catalyst and absorbent. In addition, sulfur retention ability of Bayer red mud from an alumina plant was improved by fusel salt and waste mother liquor of sodium ferrocyanide as the main sulfur fixation agent and the calcium based natural mineral materials as servicing additives.

The effects of different levels of kinetin (KT) application on the growth, biomass, contents of chlorophyll (Chl a, Chl b, and carotenoid), arsenic uptake, and activities of antioxidant enzymes in maize seedlings under arsenic (As) stress were investigated by a hydroponic experiment. The results showed that KT supplementation increased the biomass in terms of root length, root number, fresh weight, and seedling length, and KT treatments also improved the contents of $\mathrm{Chl}$ a, As uptake, and $\mathrm{Chl} \mathrm{a}: \mathrm{b}$ ratio compared to cases with As treatment alone.

Finally, graphite intended for green engineering was synthesized by noncontaminant reverse abrasion, which consists of graphite layers assembled with thickness controlled on $\mathrm{SiC}$ sandpaper as insulating substrate. Phase formation of the graphite layers was validated by $\mathrm{X}$-ray diffraction studies and its finished profile by Atomic Force Microscopy.

\section{Acknowledgments}

We would like to thank all the authors who have submitted their papers to this special issue and also to all the reviewers for their invaluable contributions to the reviewing process.

Zhaohui Li

Guocheng Lv

Jianxi Zhu 

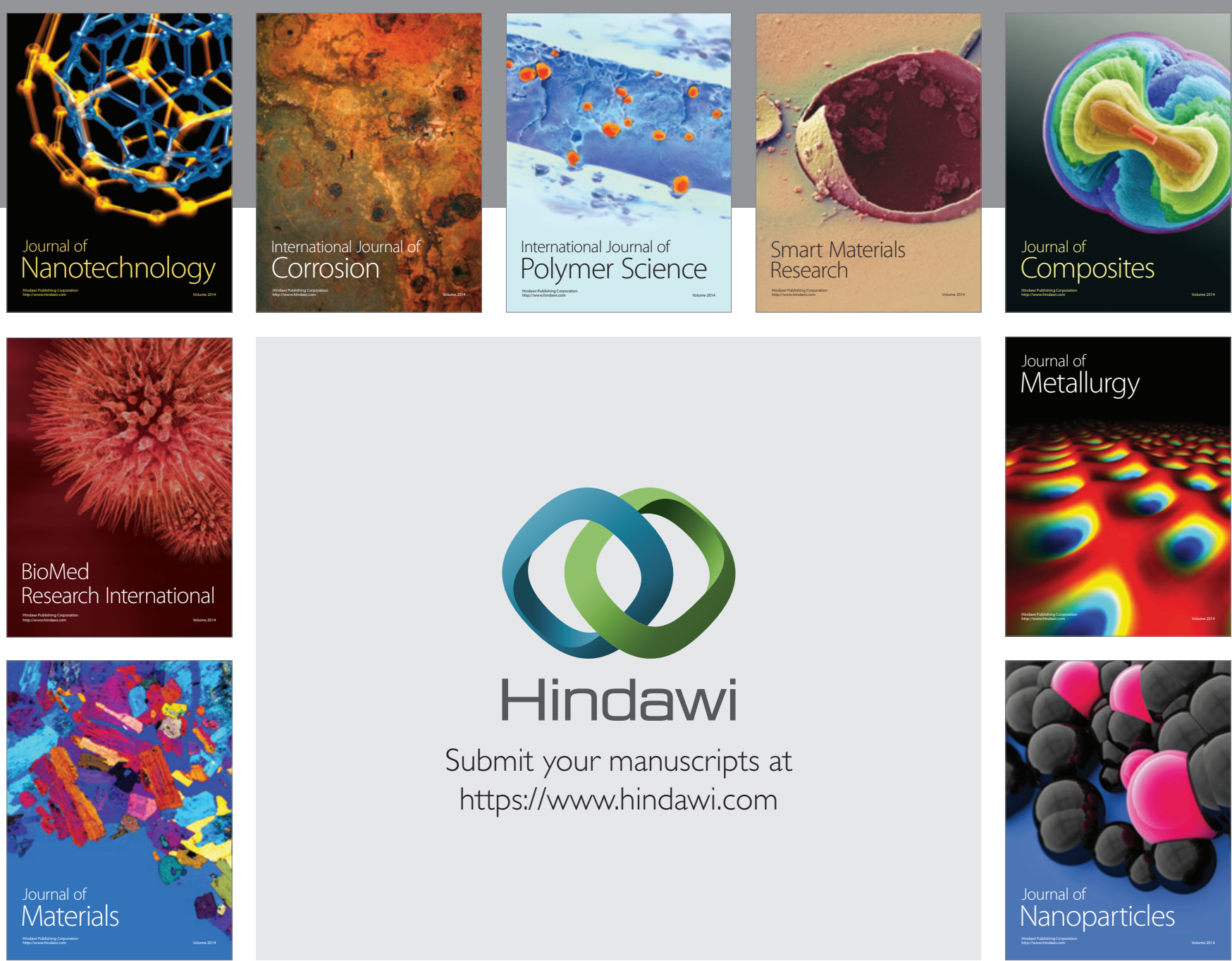

\section{Hindawi}

Submit your manuscripts at

https://www.hindawi.com

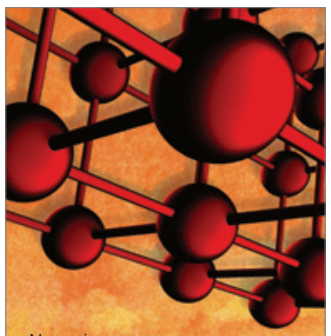

Materials Science and Engineering
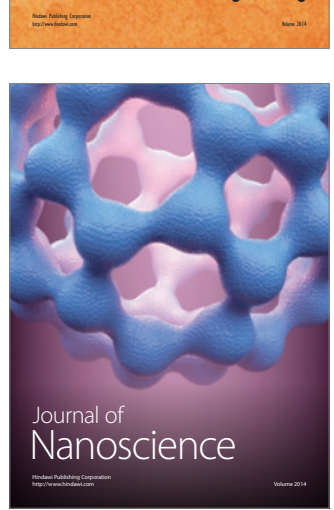
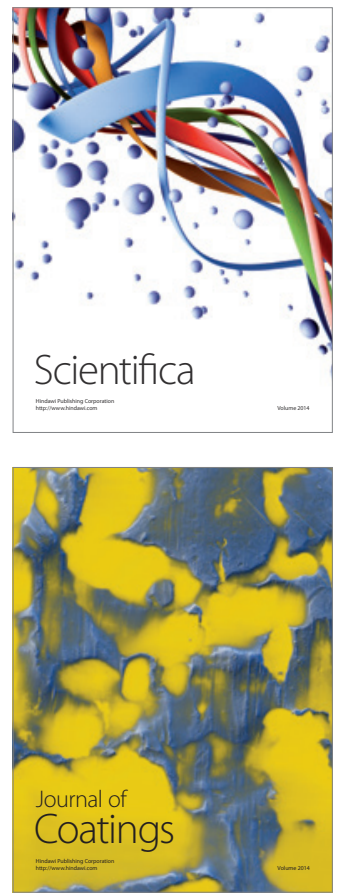
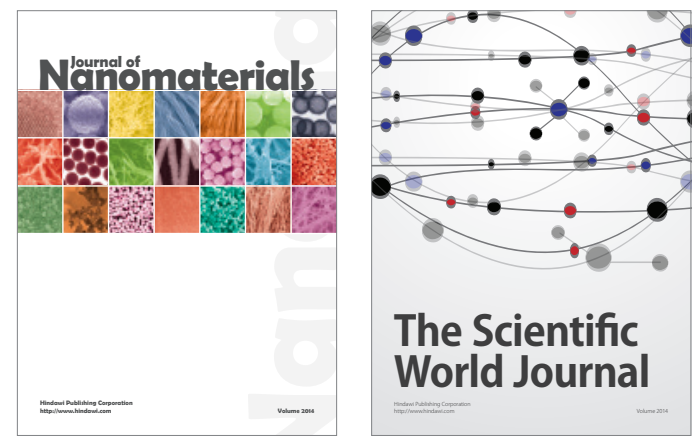

The Scientific World Journal
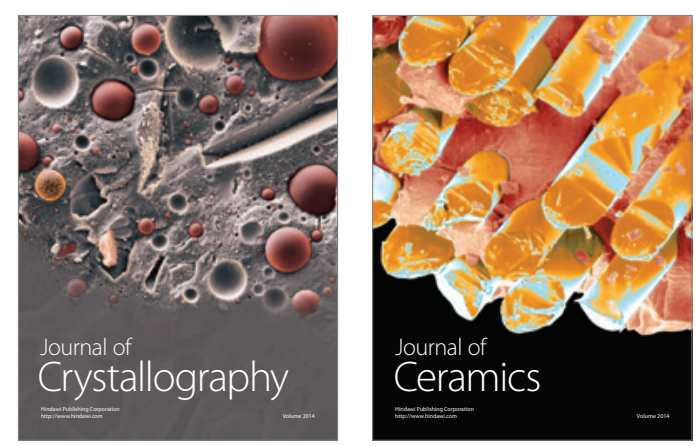
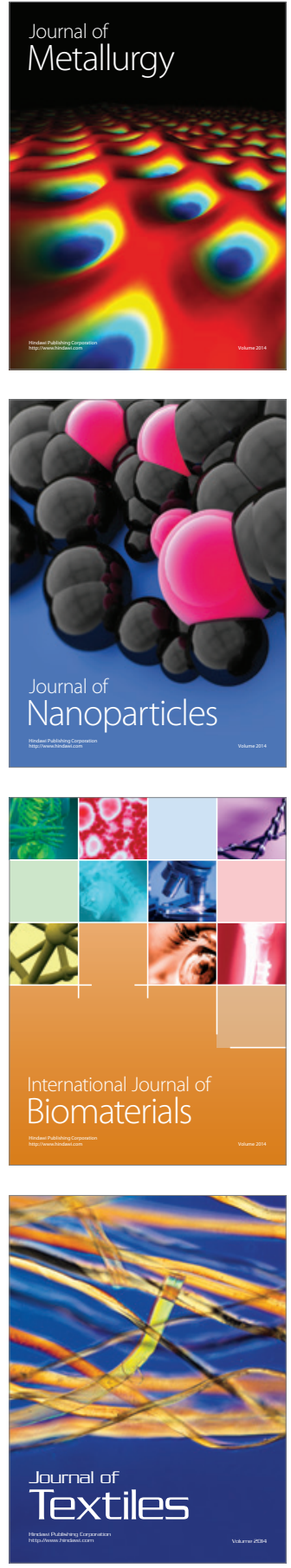